\title{
Estimation of PM10 Concentration using Ground Measurements and Landsat 8 OLI Satellite Image
}

\author{
Salah Abdul Hameed Saleh ${ }^{1^{*}}$ and Ghada Hasan ${ }^{2}$ \\ ${ }^{1}$ Nahrain University, Baghdad, Iraq \\ 2University of Technology, Baghdad, Iraq \\ *Corresponding author: Salah Abdul Hameed Saleh, Nahrain University, Baghdad, Iraq, Tel: 964-1-776-7810; E-mail: salahsrc@hotmail.com \\ Rec date: March 23, 2014; Acc date: April 21, 2014; Pub date: April 25, 2014
}

Copyright: ( 2014 Saleh et al., This is an open-access article distributed under the terms of the Creative Commons Attribution License, which permits unrestricted use, distribution, and reproduction in any medium, provided the original author and source are credited.

\begin{abstract}
The aim of this work is to produce an empirical model for the determination of particulate matter (PM10) concentration in the atmosphere using visible bands of Landsat 8 OLI satellite image over Kirkuk city- Iraq.

The suggested algorithm is established on the aerosol optical reflectance model. The reflectance model is a function of the optical properties of the atmosphere, which can be related to its concentrations.

The concentration of PM10 measurements was collected using Particle Mass Profiler and Counter in a Single Handheld Unit (Aerocet 531) meter simultaneously by the Landsat 8 OLI satellite image date. The PM10 measurement locations were defined by a handheld global positioning system (GPS).

The obtained reflectance values for visible bands (Coastal aerosol, Blue, Green and blue bands) of landsat 8 OLI image were correlated with in-suite measured PM10.

The feasibility of the proposed algorithms was investigated based on the correlation coefficient (R) and rootmean-square error (RMSE) compared with the PM10 ground measurement data. A choice of our proposed multispectral model was founded on the highest value correlation coefficient $(R)$ and lowest value of the root mean square error (RMSE) with PM10 ground data. The outcomes of this research showed that visible bands of Landsat 8 OLI were capable of calculating PM10 concentration to an acceptable level of accuracy.
\end{abstract}

Keywords: Air pollution; PM10 concentration; Lansat8 OLI image; Reflectance; Multispectral algorithms; Kirkuk area

\section{Introduction}

The main sources of air pollution in large cities around the worlds are emissions from vehicles, thermal power plants, industrial units and domestic. In last year's, air pollution problem is a major concern and becomes more and more critical in major urban centers around the globe. Air pollution strongly impacts on human health, human comfort and everyday animation.

Particulate matter (PM10) pollution consists of very small liquid and solid particles floating in the air. PM10 is a major component of air pollution that threatens both our health and our environment [1]. PM10 is a major air pollutant in cities, particularly in the developing world where maximum levels recommended by the World Health Organization (WHO) are frequently exceeded.

Particulate Matter (PM), a major air pollutant in cities, is the general term employed for a variety of solid particles and liquid droplets found in the air. The particles, with a diameter bounded by the range of $(1-10 \mu \mathrm{m})$, can constitute a significant health risk because they are small enough to penetrate the lungs and cause acute respiratory diseases. The study of particulate matter (PM) as air pollutant is important because of its effects on human health, atmospheric visibility, climate change, etc. [2,3].
Accurate mapping of air quality and its seasonal and annual changes is important for the evaluation of the current air dispersion modeling, air pollution control regulations, and other environmental climate changes. Traditionally, two general approaches to mapping air pollution can be identified: spatial interpolation and air dispersion modeling [4]. The former approaches estimate the value of pollution concentration at unsampled locations in an area of interest by interpolating the measurements from the sampled stations [1]. Most of the air quality data that currently used are interpolated from the data collected from a limited number of measuring stations located mainly in cities or estimated by the numerical air dispersion models [5].

Air pollutants can be measured from ground base stations with many different types of instruments. But these instruments are quite expensive and limited by the number of air pollutant station in each area. The limited number of the air pollutant stations and improper distributed not allowed a proper mapping of the air pollutants. Ground instruments are impractical if measurements are to be made over large areas or for continuous monitoring. So, they cannot provide a detail spatial distribution of the air pollutant over large cities.

Satellites can be the only data source in rural and remote areas where no ground-based measurements are taken [6]. A remote sensing technique was widely used for environment pollutant application such as air pollution [7]. Some studies showed that satellite data could be useful for revealing climatic and environmental implications of global air pollution [8]. Satellite data can aid in the detection, tracking, and 
understanding of pollutant transport by providing observations over large spatial domains and at varying altitudes. Satellite measurements clearly have the advantage of being the only set of measurements that provide a wide coverage. Landsat, SPOT, MODIS image data present a wide applicability for air pollution studies. Several studies have shown the possible relationships between satellite data and air pollution [9].

The study of PM concentration usually based on spatial and temporal data series measured in ground station sites in cities and rural areas [10,11]. Ground site measurements require high installation and maintenance costs. Furthermore, the data collected through these methods are effective only within the small spatial coverage around the station. So, the ground measurements cannot provide a detail spatial distribution of the particulate matter (PM) air pollutant over a large area [12]. Satellite remote sensing has provided quantitative information on Particulate matter with acceptable accuracy comparable to that of surface measurements.

MODIS images were widely used for monitoring, mapping and estimating of pm10 concentration [13]. Due to the limitations of using MODIS data include coarse MODIS spatial resolution, variation of correlation coefficients between MODIS product and PM concentration depending on the location [6] and weak correlation coefficients between MODIS product and PM concentration, air pollution researchers were looking for a more suitable satellite data. Visible and thermal bands of Landsat Thematic Mapper (TM) and Enhanced Thematic Mapper Plus (ETM7) were used widely for air pollution studies.

Recent research indicates that the observations made by the satellites may efficiently complement ground measurements. For example, efforts have been made to map concentration in suspended particulates (PM10) using TM image [14]. Wald [12] examined correlation between ground measurements air quality parameters and Landsat TM measurements in the thermal infrared band. In another study of using TM images. Ung et al. [14] found a linear correlation between reflectance derived from Landsat satellite and the integrated concentration of suspended particular PM10.

In this study, multispectral algorithm has been developed for PM10 estimation over Kirkuk city. Reflectance values in the visible bands measured by the satellite landsat8 OLI to derive the PM10 concentration. This proposed methodology derived from the correlation between the measured PM10 and Reflectance values in of Landsat 8 visible bands. Hence our study attempted to measure the PM10 using the relation with the reflectance in the four visible bands.

\section{Materials and Methods}

\section{Study area}

Kirkuk City is the capital of the Iraqi governorate of Kirkuk located at $35.47^{\circ} \mathrm{N}, 44.41^{\circ} \mathrm{E}, 236$ kilometers north of the capital, Baghdad. Kirkuk city lies $83 \mathrm{~km}$ south of Erbil, $149 \mathrm{~km}$ southeast of Mosul, $97 \mathrm{~km}$ west of Sulaymaniyah, and $116 \mathrm{~km}$ northeast (Figure 1). The population of Kirkuk city is about 600000 people. Kirkuk is characterized by being rich for its mineral resources. Oil is the main axis of its economic activities. It has the largest oil field in Iraq. In addition, it has natural gas and sulfur.

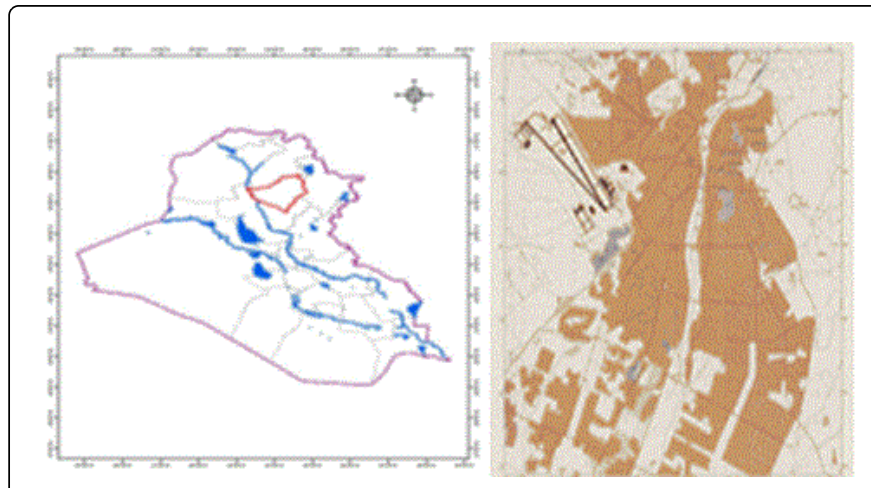

Figure 1: Study Area.

\section{Particulate matter (PM10) ground measurements}

PM10 concentrations were collected simultaneously with the image acquisition date at 13 locations around KIRKUK city using Particle Mass Profiler and Counter in a Single Handheld Unit (Aerocet 531). It is a small, handheld, battery operated and completely portable unit. This unit provides both particle counts and mass PM measurements as stored data logged values, real-time networked data, or printed results.

\section{Landsat8 OLI image}

Landsat 8 OLI image is used in this work, the acquisition date of the Landsat 8 OLI image at Path/Row 169/35 on 10th February 2014. Landsat 8 OLI scene was downloaded from the United States Geological Survey (USGS) with the following information:

\section{- Scene ID: LC81690352014041LGN00}

- Sensor: OLI

- Acquisition Date: 10 Feb 2014

- Date Updated: 10 Feb 2014

- Path: 169

- Row: 35

- Cloud Cover: 2

- Sun Elevation: 34.80576

- Sun Azimuth: 151.0065

- Receiving Station: LGN

- Scene Start Time: 10 Feb 2014 07:39:39 GMT

- Month: 2

- Year: 2014

Landsat 8 Operational Land Imager (OLI) and Thermal Infrared Sensor (TIRS) images consist of nine spectral bands with a spatial resolution of 30 meters for Bands 1 to 7 and 9. The resolution for Band 8 (panchromatic) is 15 meters. Thermal bands 10 and 11 are collected at 100 meters, but are resampled to 30 meter in delivering data product. Approximate scene size is $170 \mathrm{~km}$ north-south by $183 \mathrm{~km}$ east-west, Table 1.

Visible bands 1, 2, 3 and 4 of Landst 8 OLI image dated 10 Feb. 2014 for Kirkuk area were used in this study (Figure 2). 
Citation: Saleh SAH, Hasan G (2014) Estimation of PM10 Concentration using Ground Measurements and Landsat 8 OLI Satellite Image. J Geophys Remote Sens 3: 120. doi:10.4172/2169-0049.1000120

Page 3 of 6

\begin{tabular}{|c|c|c|c|}
\hline \multirow{12}{*}{$\begin{array}{l}\text { Landsat } 8 \text { Operational Land Imager (OLI) and Thermal Infrared Sensor (TIRS) Launched } \\
\text { February } 11,2013\end{array}$} & Bands & $\begin{array}{l}\text { Wavelength } \\
\text { (micrometers) }\end{array}$ & $\begin{array}{l}\text { Resolution } \\
\text { (meters) }\end{array}$ \\
\hline & $\begin{array}{l}\text { Band } 1-\text { Coastal } \\
\text { aerosol }\end{array}$ & $0.43-0.45$ & 30 \\
\hline & Band 2 - Blue & $0.45-0.51$ & 30 \\
\hline & Band 3 - Green & $0.53-0.59$ & 30 \\
\hline & Band 4 - Red & $0.64-0.67$ & 30 \\
\hline & $\begin{array}{l}\text { Band } 5 \text { - Near Infrared } \\
\text { (NIR) }\end{array}$ & $0.85-0.88$ & 30 \\
\hline & Band 6 - SWIR 1 & $1.57-1.65$ & 30 \\
\hline & Band 7 - SWIR 2 & $2.11-2.29$ & 30 \\
\hline & Band 8 - Panchromatic & $0.50-0.68$ & 15 \\
\hline & Band 9 - Cirrus & $1.36-1.38$ & 30 \\
\hline & $\begin{array}{l}\text { Band } 10-\text { Thermal } \\
\text { Infrared (TIRS) } 1\end{array}$ & $10.60-11.19$ & 100 \\
\hline & $\begin{array}{l}\text { Band } 11-\text { Thermal } \\
\text { Infrared (TIRS) } 2\end{array}$ & $11.50-12.51$ & 100 \\
\hline
\end{tabular}

Table 1: Spectral and Spatial characteristics of Landsat 8 OLI Bands.

\section{Aerosol Optical Thickness (AOT) and PM10 Correlation}

The standard Landsat 8 products provided by the USGS EROS Center consist of quantized and calibrated scaled Digital Numbers (DN) representing multispectral image data acquired by both the Operational Land Imager (OLI) and Thermal Infrared Sensor (TIRS). Typically, the received DN values data can be converted into radiances by simple linear Radiometric correction is applied by transforming the values of $\mathrm{DN}$ to radiance or reflectance values. There are different steps of radiometric calibration. The first converts the sensor DN to atsensor radiances using sensor calibration information $[15,16]$. The second is the transformation of the at-sensor radiances to radiances at the earth's surface. Radiometric correction is applied by transforming the values of DN to radiance or reflectance values through the algorithm as follows (Landsat 8 Data product USGS):

\section{Conversion to TOA radiance}

OLI bands data can be converted to TOA spectral radiance using the radiance rescaling factors:

$$
L \lambda=M \mathrm{~L} Q \mathrm{cal}+A \mathrm{~L} \ldots(1)
$$

Where:

$$
\left.L \lambda=\text { TOA spectral radiance (Watts } /\left(\mathrm{m} 2^{\star} \operatorname{srad}^{\star} \mu \mathrm{m}\right)\right) \text {. }
$$

$M \mathrm{~L}=$ Band-specific multiplicative rescaling factor from the metadata (Radiance_Mult_Band_x, where $\mathrm{x}$ is the band number).

$A \mathrm{~L}=$ Band-specific additive rescaling factor from the metadata (Radiance_Add_Band_x, where $\mathrm{x}$ is the band number). (DN).

Qcal = Quantized and calibrated standard product pixel values
OLI spectral radiance data can also be converted to TOA planetary reflectance using reflectance rescaling coefficients provided in the landsat8 OLI metadata file. The following equation is used to convert $\mathrm{DN}$ values to TOA reflectance for OLI image:

$$
\rho \lambda^{\prime}=M \rho Q \mathrm{cal}+A \rho \ldots . .(2)
$$

Where:

$\rho \lambda^{\prime}=$ TOA planetary reflectance, without correction for solar angle. Note that $\rho \lambda$ ' does not contain a correction for the sun angle.

$M \rho=$ Band-specific multiplicative rescaling factor from the metadata (Reflectance_Mult_Band_x, where $\mathrm{x}$ is the band number)

$A \rho=$ Band-specific additive rescaling factor from the metadata (Reflectance_Add_Band_x, where $\mathrm{x}$ is the band number)

Qcal $=$ Quantized and calibrated standard product pixel values (DN)

TOA reflectance with a correction for the sun angle is then:

$\rho \lambda=\frac{\rho \lambda^{\prime}}{\cos (\theta S Z)}=\frac{\rho \lambda^{\prime}}{\sin (\theta S E)}(3)$

Where:

$\rho \lambda=$ TOA planetary reflectance

$\theta \mathrm{SE}=$ Local sun elevation angle. The scene center sun elevation angle in degrees is provided in the metadata (Sun Elevation).

$\theta \mathrm{SZ}=$ Local solar zenith angle; $\theta \mathrm{SZ}=90^{\circ}-\theta \mathrm{SE}$.

The atmospheric reflectance was then related to the PM10 using the regression algorithm analysis. The algorithm of AOT for single band or wavelength $(\lambda)$ is simplified as $[13,17]$ :

$\operatorname{AOT}(\lambda)=\operatorname{an} \mathrm{R}(\lambda) \ldots(4)$ 
Citation: Saleh SAH, Hasan G (2014) Estimation of PM10 Concentration using Ground Measurements and Landsat 8 OLI Satellite Image. J Geophys Remote Sens 3: 120. doi:10.4172/2169-0049.1000120

Page 4 of 6

Equation (4) is rewritten into multiband equation as:

$A O T(\lambda)=$ aо $R \lambda 1+a 1 R \lambda 2+a 2 R \lambda 3+a 3 R \lambda 4 \ldots . . .(5)$

Where $\mathrm{R} \lambda$ is the atmospheric reflectance $(i=1,2,3 \ldots$ Corresponding to wavelength for satellite), and aj is the algorithm coefficient $(j=0,1,2, \ldots)$ is empirically determined.

The relation between PM and AOT is derived for a single homogeneous atmospheric layer containing spherical aerosol particles.

Hence, it can be expected that the parameter PM correlates better with AOT directly. Using the information, obtained by the spectral AOT retrieval, a method has been developed to retrieve particulate matter concentrations.

By substituting AOT in term of PM10, into the equation (5), the algorithm of PM10 with spectral reflectance of multi-band wavelengths $(\lambda \mathbf{i})$ is simplified as $[18,19]$ :

$$
P M 10=\text { ao } R \lambda 1+a 1 R \lambda 2+a 2 R \lambda 3+a 3 R \lambda 4 \text {....(6) }
$$

Where $\mathrm{R} \lambda \mathrm{i}$ is the atmospheric reflectance $(i=1,2,3,4$.. corresponding to satellite bands), and aj is the algorithm coefficient $(j=0,1,2,3 \ldots .$.$) are$ empirically determined.

Several studies showed that PM10 and AOT have linear relationship correlation [20-22] found that correlation as high as 0.78 to 0.95 are retrieved between the AOT values and PM10 measurements.

\section{Results}

The digital numbers of the four visible bands of Landsat 8 OLI were extracted corresponding to the locations of in situ PM10 measurements around Kirkuk city and converted into irradiance and then to reflectance. The relationship between extracted spectral reflectance from Landsat 8 OLI satellite image with PM10 ground measurements were examined and investigated through correlation analysis. The scatter plot of Landsat 8 visible bands reflectance versus PM10 is shown in Figure 3.

Table 2 summarizes the linear correlation coefficient analysis between spectral reflectance for visible bands of Landsat 8 OLI image and ground PM10 air pollution concentrations. Analysis of Correlation shows that high significant correlations between reflectance values of four visible Landsat 8 OLI bands with in-suite PM10 concentration. Analysis correlation shows that band3 (Green, $0.53-0.59 \mu \mathrm{m}$ ) reflectance was highly correlated with ground measure PM10 than the reflectance of other bands $[23,24]$.

Then the reflectance values were referred to the PM10 using the regression algorithm to examine. The reflectance values were due to the high correlation coefficient $(\mathrm{R})$ and lowest root mean square error (RMSE) value with the PM10 ground measurements.

Many algorithms were made up to correlate satellite reflectance and the PM10 values. These algorithms were used to calculate PM10 concentration from the reflectance values of Landsat 8 OLI visible bands. Table 3 shows various types of algorithms applied to calculate PM10 from Landsat8 OLI reflectance values. The proposed regression model to be applied based on highest correlation coefficient (R) and lowest root mean square error (RMSE) value as stated in the Table 3.

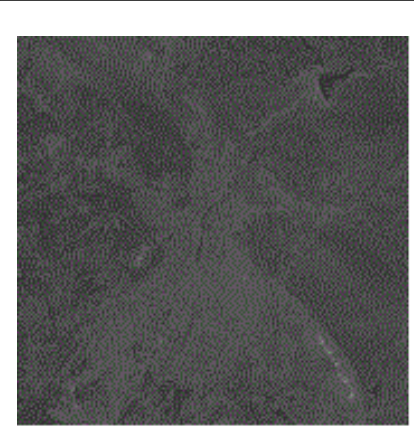

Band 1-Coasta1 aerosol( $(0.43-0.45 \mu \mathrm{m})$

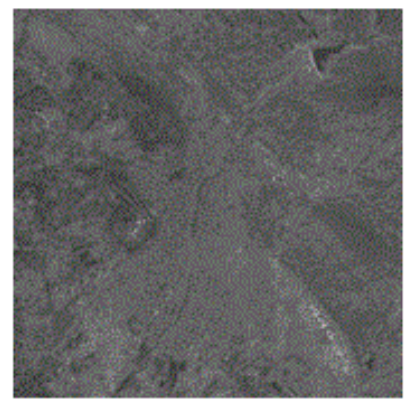

Band 3-Green $(0.53-0.59 \mu \mathrm{m})$

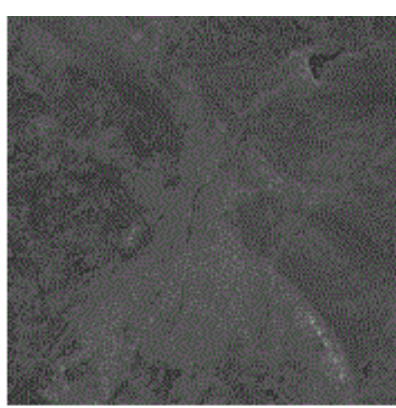

Band 2-B1ve $(0.45-0.51 \mu \mathrm{m})$

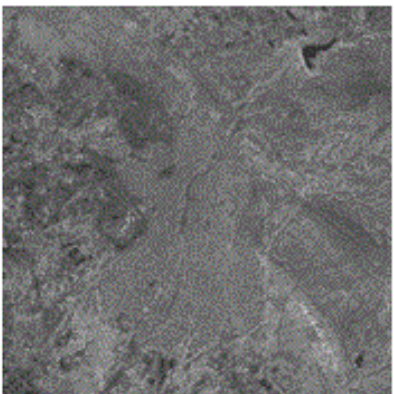

B and 4-Red $(0.64-0.67 \mu \mathrm{m})$
Figure 2: Landsat 8 OLI Bands 1, 2, 3 and 4 images for Kirkuk city at $10 \mathrm{Feb} 2014$.

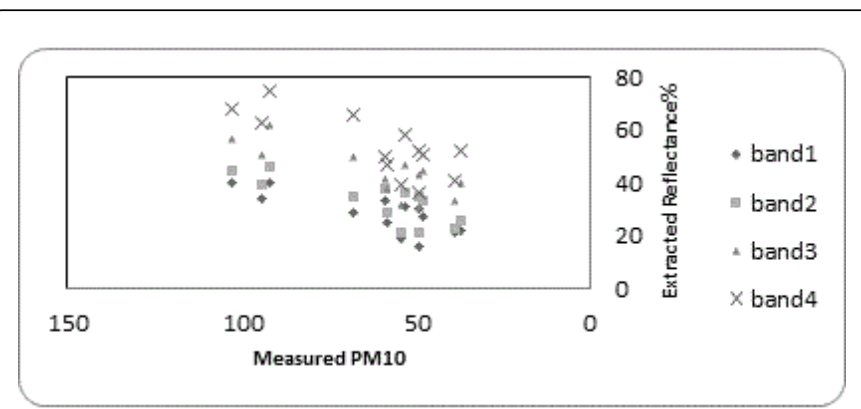

Figure 3: Spectral reflectance of visible bands 1,2, 3 and 4 of Landsat 8 OLI image dated 10 Feb 2014 versus ground measured PM10.

Algorithm number (13) selected to be our proposed algorithm due to its highest correlation coefficient of (0.834) and lowest root mean square error (RMSE) value of (11.836) between the measured and calculated PM10 values. The accuracy and validation of proposed algorithm results were performed using PM10 ground measurements and calculated PM10 by our algorithm.

\begin{tabular}{|l|l|l|l|l|}
\hline & Band 1 & Band 2 & Band 3 & Band 4 \\
\hline PM10 & 0.799 & 0.785 & 0.802 & 0.77 \\
\hline
\end{tabular}

Table 2: Correlation analysis between PM10 ground measurements and Landsat 8 OLI reflectance.

Figure 4 shows the measured and calculated PM10 with a correlation coefficient of $(\mathrm{R}=0.833)$. That means our multispectral 
Page 5 of 6

model is going quite well in calculating PM10 from Landsat 8 OLI satellite data for Kirkuk city.

\begin{tabular}{|c|c|c|c|}
\hline $\begin{array}{l}\text { Algorith } \\
\text { m No. }\end{array}$ & Algorithm & $\mathbf{R}$ & RMSE \\
\hline 1 & $\left.\mathrm{PM} 10{ }^{*}\right)=2.26 \mathrm{~b}\left({ }^{* *}\right) 1-2.267$ & 0.799 & 12.87 \\
\hline 2 & $\mathrm{PM} 10=2.04 \mathrm{~b} 2-4.406$ & 0.785 & 13.263 \\
\hline 3 & $\mathrm{PM} 10=1.81 \mathrm{~b} 3-17.728$ & 0.802 & 20.986 \\
\hline 4 & $P M 10=1.39$ b4-13.099 & 0.77 & 18.772 \\
\hline 5 & PM10 $=3.56$ b1-1.17 b2-0.255 & 0.79 & 13.127 \\
\hline 6 & $P M 10=1.21 b 1+0.98$ b3- 12.903 & 0.83 & 20.986 \\
\hline 7 & $\mathrm{PM} 10=1.56 \mathrm{~b} 1+0.51 \mathrm{~b} 4-9.458$ & 0.789 & 13.156 \\
\hline 8 & $\mathrm{PM} 10=0.64 \mathrm{~b} 2+1.27 \mathrm{~b} 3-15.226$ & 0.805 & 20.986 \\
\hline 9 & $\mathrm{PM} 10=1.24 \mathrm{~b} 2+0.60 \mathrm{~b} 4-11.170$ & 0.832 & 11.879 \\
\hline 10 & $\mathrm{PM} 10=4.36 \mathrm{~b} 1-3.50 \mathrm{~b} 2+1.51 \mathrm{~b} 3-12.615$ & 0.81 & 20.986 \\
\hline 11 & $P M 10=0.41 b 2+2.27 b 3-0.66 b 4-16.174$ & 0.802 & 20.985 \\
\hline 12 & $P M 10=0.99 b 1+1.62 b 3-0.45 b 4-13.481$ & 0.817 & 20.986 \\
\hline 13 & 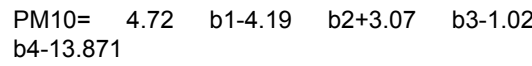 & 0.834 & 11.836 \\
\hline
\end{tabular}

Table 3: Regression results (R) and (RMSE) using different forms of algorithms. ${ }^{*}$ ) Calculated PM10 by algorithms, $\left({ }^{* *}\right)$ b1,b2,b3 and b4 are the reflectance values for band1,band2, band 3 and band 4 of Landsat 8 OLI .

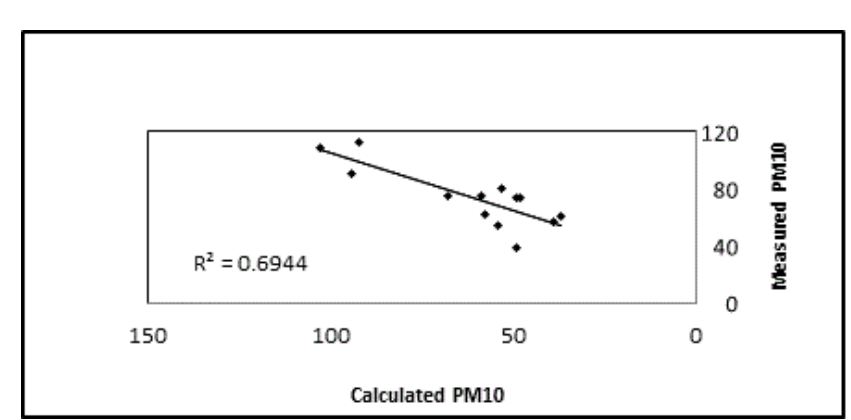

Figure 4: Correlation between ground measured and calculated PM10 concentration.

\section{Conclusion}

Landsat8 OLI image was successfully used for calculation of PM10 concentration over Kirkuk City -IRAQ. Our proposed multispectral algorithm of PM10 algorithm is based on the aerosol optical reflectance model. The result indicates that the air pollution PM10 can be calculated, by our model, with a high degree of accuracy using the visible bands reflectance value of Landsat 8 OLI image.

A good agreement was found between in-suite PM10 measurement and calculated PM10. Our algorithm produced a high correlation between the measured and calculated PM10 concentration. The study proved the efficiency of our multispectral model of estimation of
PM10 concentration based on the visible bands of Landsat 8 OLI satellite image with Kirkuk region.

The results of this study indicate that air pollution can be mapped using satellite information to provide a bigger area of coverage. Further investigation may extend out to raise the accuracy of our algorithm by using thermal infrared band data in combination with visible bands of landsat8 OLI.

\section{Acknowledgements}

The authors are indebted to Environmental research center University of Technology - Baghdad for the kind permission of using particle mass profiles and count unit (Aerocet 531) in this research.

\section{References}

1. Masitah A, Zaini H, Lee SK (2007) PM10 and Total Suspended Particulates (TSP) Measurements in Various Power Stations. The Malaysian Journal of Analytical Sciences 11: 255-261.

2. Leili M, Naddafi K, Nabizadeh R, Yunesian M, Mesdaghinia A (2008) The study of TSP and PM10 concentration and their heavy metals content in central area of Tehran, Iran. Air Quality, Atmosphere \& Health 1: 159-166.

3. WHO (1999) Air Quality Guidelines. Protection of Human Environment, World Health Organization, Geneva.

4. Elliott P, Cuzick J, English D, Stern R (1996) Geographical and Environmental Epidemiology: Methods for Small-area Studies. Oxford: Oxford University Press, UK.

5. Retalis A, Sifakis N (2010) Urban aerosol mapping over Athens using the differential textural analysis (DTA) algorithm on MERIS-ENVISAT data. ISPRS Journal of Photogrammetry and Remote Sensing 65: 17-25.

6. WijeratneI K, Bijker W (2006) Mapping Dispersion of Urban Pollution with Remote Sensing. International Archives of Photogrammetry, Remote Sensing, and Spatial Information Sciences 34: 125-130.

7. Ung A, Wald L, Ranchin T, Weber C, Hirsch J, et al. (2001) Satellite data for Air Pollution Mapping over a City- Virtual Stations.

8. Akimoto H (2003) Global Air Quality and Pollution. Science 302: 1716-1719.

9. Ung A, Weber C, Perron G, Hirsch J, Kleinpeter J, et al. (2001) Air Pollution Mapping over a City - Virtual Stations and Morphological Indicators. 10th International Symposium "Transport and Air Pollution", Colorado, USA.

10. Retalis A, Cartalis C, Athanassious E (1999) Assessment of the distribution of aerosols in the area of Athens with the use of Landsat Thematic Mapper data. Int J Remote Sensing 20: 939-945.

11. Sifakis N, Gkoufa A, Soulakellis N (1998) Integrated Computational Assessment Via Remote Observation System.

12. Wald L, Baleynaud JM (1999) Observed air quality over city of Nantes by means of Landsat Thermal Infrared data. International journal of Remote Sensing 20: 947-959.

13. Hadjimitsis DG (2009) Aerosol optical thickness (AOT) retrieval over land using satellite image-based algorithm, Air Quality. Atmosphere \& Health-An International Journal 2: 89-97.

14. Ung A, Wald L, Ranchi T, Weber C, Hirsch J, et al. (2003) Air pollution mapping: relationship between satellite made observation and air quality parameters. 12th International Symposium ,Transport and Air Pollution, Avignon, France.

15. Liu CH, Chen AJ, Liu GR (1996) An image-based retrieval algorithm of aerosol characteristics and surface reflectance for satellite images. International Journal of Remote Sensing 17: 3477-3500.

16. Lim HS, MatJafri MZ, Abdullah K, Mohd NS (2009) Optimal Estimation of Surface Reflectance from Landsat TM Visible and Mid Infrared Data over Penang Island. CiteSeer. 
Citation: Saleh SAH, Hasan G (2014) Estimation of PM10 Concentration using Ground Measurements and Landsat 8 OLI Satellite Image. J Geophys Remote Sens 3: 120. doi:10.4172/2169-0049.1000120

Page 6 of 6

17. Lim HS, MatJafri MZ, Abdulla K, Mohd NS, Sultan AS (2004) Remote Sensing of PM10 From Landsat TM Imagery. 25th ACRS 2004 Chiang Mai, Thailand.

18. Nadzri O, Mohd ZMJ, Lim HS (2010) Estimating Particulate Matter Concentration over Arid Region Using Satellite Remote Sensing: A Case Study in Makkah, Saudi Arabia. Modern Applied Science 4: 131-142.

19. Nadzri O, Mohd ZMJ, Lim HS, Abdullah K (2010) Satellite Retrieval Optical Thickness over Estimating Arid Region: Case Study over Makkah, Mina and Arafah, Saudi Arabia. Journal of Applied Sciences 10 3021-3031.

20. Glantz P, Johansson C, Hoyningen WV (2007) Inter-comparison between satellites retrieved AOT and in-situ PM2.5. The Remote Sensing of Atmospheric Constituents from Space.
21. Chu DA, Kaufman YJ, Zibordi G, Chern JD, Jietai M, et al. (2003) Global monitoring of air pollution over land from the Earth Observing SystemTerra Moderate Resolution Imaging Spectroradiometer (MODIS). Journal of Geophysical Research 108

22. Sifakis N, Soulakellis N, Paronis D, Mavrantza R (2002) Manual of EO image processing codes.

23. http://landsat.usgs.gov/landsat8.php

24. Lim HS (2003) Total Suspended Solids Mapping Using Digital Camera Imagery Taken From Light Aircraft. 